\title{
PHOTOOXIDATION OF SILOXANE POLYMERS UNDER VACUUM ULTRAVIOLET IRRADIATION.
}

\author{
V.N. VASILETS, A..V. KOVALCHUK, A.N. PONOMAREV \\ Institute for Energy Problems of Chemical Physics \\ Chernogolovka, Noginsk dist., Moscow reg., RUSSLA, 142432
}

Vacuum ultraviolet(VUV) irradiation (wavelength 147 $\mathrm{nm}$ ) of siloxane polymers in the presence of air was studied using ATR FTIR and XPS spectroscopy. The ATR FTIR study revealed the formation of $\mathrm{CO}$ and $\mathrm{OH}$ groups in the surface layer depending on irradiation time and air pressure. The concentrations of $\mathrm{CO}$ and $\mathrm{OH}$ groups level off with the increase of irradiation time and pass through the maximum value with the increase of pressure in the range of 0.1100 torr. The XPS study of irradiated polysiloxane films demonstrated that intermolecular crosslinking via oxygen atoms also takes place on the polymer surface. The concentrations of the most important oxygen species $O$ and O3, produced by VUV photolysis of air and coming to the polymer surface were calculated for the air pressure range 0.1-100torr. The photooxidation mechanism for siloxane polymers under VUV irradiation in air has been proposed.

\section{Introduction}

Interest in using siloxane polymers has been steadily increasing because of their good biocompartibility, high gas permeability, unique optical and mechanical properties [1,2]. A study of VUV irradiation of siloxane polymers is of great interest for understanding the mechanism of photooxidation and possible application of this process for surface modification purposes. In this work we have investigated the kinetics and mechanism of chemical changes occuring in the surface layer of siloxane polymers under the action of resonant vacuum ultraviolet irradiation with the wavelength $147 \mathrm{~nm}$ in the presence of air.

\section{Experimental methods.}

Samples of siloxane polymers (diameter $10 \mathrm{~mm}$, thickness $1-3 \mathrm{~mm}$ ) were irradiated in vacuum chamber at air pressure $0.1-100$ torr, flow rate 20 $\mathrm{cm}^{3}(\mathrm{STP}) / \mathrm{min}$ and room temperature. The hollow cathode gas discharge resonant Xe lamp KsR-2A [3] equipped with $\mathrm{MgF}_{2}$ window and located at a distance $30 \mathrm{~mm}$ from 
the polymer surface has been used. The radiation intensity was measured by "sun blind" vacuum photodiod.

IR spectra of polymer surface layer were recorded on Perkin- Elmer model 1720X FTIR spectrometer using attenuated total reflection technique ( Harrick ATR attachment, KRS-5 prism, angle $45^{\circ}, 25$ reflections).

The treated polymer surfaces were also analyzing by X-ray photoelectron spectroscopy on Kratos model XSAM 800 spectrometer employing $\mathrm{MgK}_{\mathrm{a}}$ exciting radiation. The spectra of $\mathrm{C}_{1 s}, \mathrm{O}_{1 s}$ and $\mathrm{Si}_{2 \mathrm{p}}$ regions were registrated.

The structures of two investigated siloxane polymers are shown below:

$\left[\begin{array}{c}\mathrm{CH}_{3} \\ -\mathrm{Si}-\mathrm{O}- \\ \mathrm{CH}_{3}\end{array}\right]$ $\left[\begin{array}{c}\mathrm{C}_{6}{ }^{\mathrm{H}_{5}} \\ -\mathrm{Si}_{\mathrm{i}}-0- \\ \mathrm{C}_{6}{ }^{\mathrm{H}_{5}}\end{array}\right]$

$m=200$

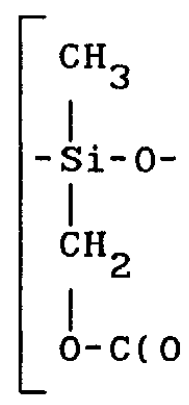

$n=5-9$

( I)<smiles>CCC(C)O[Si](C)(C)C</smiles>

\section{Results and discussion.}

Fig. 1 shows ATR FTIR spectra of polymer I before (curve 1) and after (curve 2) VUV treatment as well as the difference spectrum (curve 3). Two new bands observed in the regions $3000-3400 \mathrm{~cm}^{-1}$ and $1700-1740 \mathrm{~cm}^{-1}$ in the difference spectrum can be attributed to $\mathrm{OH}$ and $\mathrm{CO}$ stretching vibration respectively.

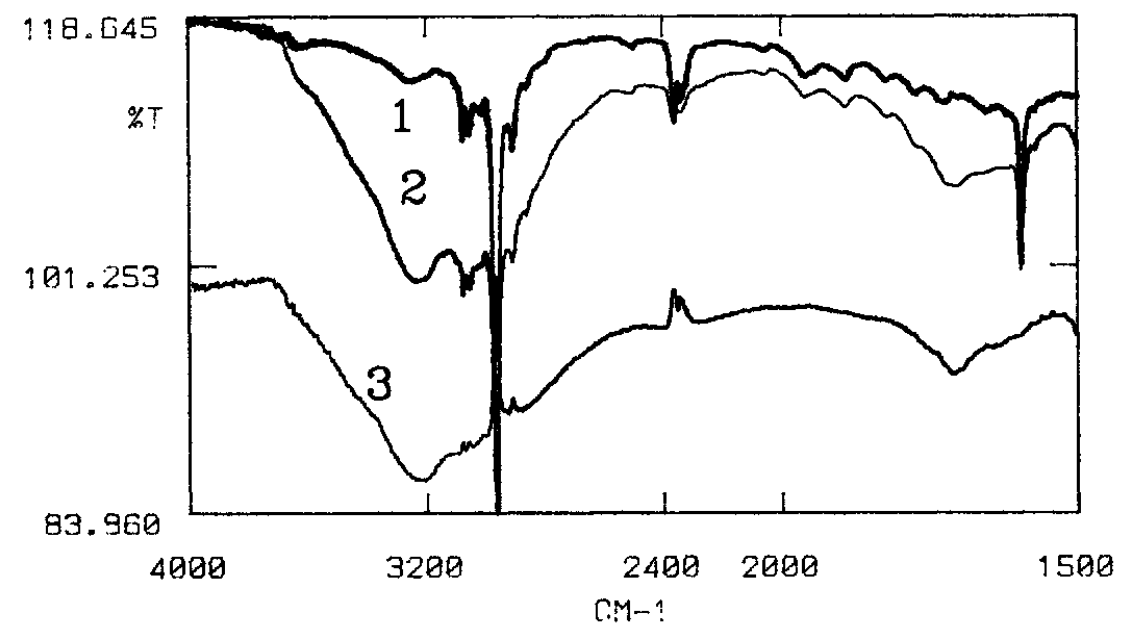

Fig.1 IR (ATR) spectra of the polymer I:1 - untreated,

2 - VUV treated( $t=30$ min, $p=3$ torr),

3 - difference spectrum.

Table 1 summarize the results of XPS surface study of polymer 1 before and 
after irradiation.

Table 1. Summary of changes in elemental composition due to VUV treatment of polymer I. 1-untreated sample, 2-VUV treated sample $(t=20 \mathrm{~min}, p=2.5$ torr, $l=3 \mathrm{~cm})$

\begin{tabular}{|c|c|c|c|c|c|c|}
\hline \multirow{5}{*}{$\begin{array}{c}\text { N } \\
\text { smp. }\end{array}$} & \multicolumn{3}{|c|}{ Si2p } & c1s & $01 \mathrm{~s}$ & \\
\hline & $\begin{array}{l}\left(\mathrm{CH}_{3}\right)_{2}{ }^{-\mathrm{Si}-} \\
-(-\mathrm{O})_{2}\end{array}$ & $\begin{array}{l}\left(\mathrm{CH}_{3}\right)-\mathrm{Si}- \\
-(-\mathrm{O})_{3}\end{array}$ & $\mathrm{Si}-(-0)_{4}$ & - & - & \\
\hline & \multicolumn{5}{|c|}{ Binding energies. } & \\
\hline & 103.5 & 103.2 & 104.0 & 285 & 532.5 & \\
\hline & \multicolumn{5}{|c|}{ Atoms concentrations, $\%$} & $\begin{array}{l}\text { Concentr. } \\
\text { crosslinks } \\
\text { per } \\
100 \text { atoms }\end{array}$ \\
\hline 1 & 21 & - & - & 58 & 21 & - \\
\hline 2 & 14 & 2. 9 & 2.3 & 52.8 & 28 & 39 \\
\hline
\end{tabular}

The $\mathrm{C}_{1 \mathrm{~s}}(285.0 \mathrm{eV}), \mathrm{O}_{1 \mathrm{~s}}(532.5 \mathrm{eV})$ and $\mathrm{Si}_{2 \mathrm{p}}(103.5 \mathrm{eV})$ XPS peaks were investigated. Three components were used for simulation of $\mathrm{Si}_{2 p}$ peak. The first one is due to $\mathrm{Si}$ atoms in $\mathrm{Si}\left(\mathrm{O}_{2}\right)$ environment $(103.5 \mathrm{eV})$, the second one is attributed to $\mathrm{Si}$ atoms bonded to three oxygen atoms $\mathrm{Si}\left(\mathrm{O}_{3}\right)(103.2 \mathrm{eV})$ and the third one is due to $\mathrm{Si}$ atoms bonded to four oxygen atoms $\mathrm{Si}\left(\mathrm{O}_{4}\right)(104.0 \mathrm{eV})$. The presence of this three components in siloxane polymers exposed to oxygen plasma afterglow was observed and identified earlier [2] by using appropriate model compounds. Analysis of possible structures of treated polymers based on $\mathrm{C}, \mathrm{O}$, and $\mathrm{Si}$ atomic concentrations obtained from XPS spectra shows that $\mathrm{Si}\left(\mathrm{O}_{3}\right)$ and $\mathrm{Si}\left(\mathrm{O}_{4}\right)$ structures could be attributed to the intermolecular crosslinks formed via oxygen atoms. Therefore as indicated in Table 1 about 39\% of $\mathrm{Si}$ atoms have been involved in intermolecular crosslinks by VUV irradiation. Comparing in wide shape of $\mathrm{C}_{1 \mathrm{~s}}$ spectra of irradiated polymer with that of untreated sample also 
suggests the formation of $\mathrm{CO}$ and $\mathrm{COH}$ groups under irradiation. Very similar changes in structure appeared in the formation of $\mathrm{CO}, \mathrm{OH}$ groups and intermolecular crosslinks were observed for polymer II after irradiation.

It is evident that changes in structure caused by the simultaneous action of incident VUV radiation and active oxygen species $\mathrm{O}, \mathrm{O}_{3}, \mathrm{O}_{2}\left({ }^{1_{\Delta}}\right)$ etc. produced by VUV photolysis of air and come to the polymer surface. The gaseous products eliminated from polydimethylsiloxane under VUV $147 \mathrm{~nm}$ irradiation were studied earlier [4] by masspectrometric method. It has been shown that $\mathrm{H}_{2}, \mathrm{CH}_{4}$, and $\mathrm{C}_{2} \mathrm{H}_{6}$ were the main products of PDMS photolysis in vacuum. Initial quantum yields were found to be $1.2^{*} 10^{-2}, 6.4^{*} 10^{-2}$ and $1.0^{*} 10^{-2}$ for $\mathrm{H}_{2}, \mathrm{CH}_{4}$ and $\mathrm{C}_{2} \mathrm{H}_{6}$ respectively. Analysis of experimental data led the authors to the conclusion that removal of $\mathrm{H}$ and $\mathrm{CH}_{3}$ radicals was the main primary processes induced by VUV irradiation. Based on these conclusions and on the values of quantum yields obtained for stable gaseous products the quantum yields of polymer macroradicals - $\mathrm{Si}\left(\mathrm{CH}_{3}\right)_{2}-\mathrm{O}-\mathrm{Si}\left(\mathrm{CH}_{3}\right)-$ (1) and $\mathrm{Si}\left(\mathrm{CH}_{3}\right)_{2}-\mathrm{O}-\mathrm{Si}\left(\mathrm{CH}_{3}\right)\left(\mathrm{CH}_{2}\right)-$ (2) formed as a result of $\mathrm{CH}_{3}$ and $\mathrm{H}$ abstraction were calculated to be $8.2^{*} 10^{-2}$ and $8.8^{*} 10^{-2}$ respectively.

Among active oxygen particles, formed as a result of VUV absorption in air the $\mathrm{O}$ and $\mathrm{O}_{3}$ species play the most important role in surface photooxidation. processes. Actually these particles have the maximum rate constants in the reactions with surface stable groups and with macroradicals produced under VUV irradiation. The processes of formation and destruction of $\mathrm{O}$ and $\mathrm{O}_{3}$ active species can be describe by the following set of basic reactions:

$$
\begin{array}{ll}
\mathrm{O}_{2}+\mathrm{h} v \rightarrow 2 \mathrm{O} & \varphi_{1}=2 \\
\mathrm{O}+\mathrm{O}_{2}+\mathrm{O}_{2} \rightarrow \mathrm{O}_{3}+\mathrm{O}_{2} & \mathrm{k}_{1}=3.5^{*} 10^{-34} \mathrm{~cm}^{6} / \mathrm{mole}^{2} \mathrm{~s} \\
\mathrm{O}+\mathrm{O}_{2}+\mathrm{N}_{2} \rightarrow \mathrm{O}_{3}+\mathrm{N}_{2} & \mathrm{k}_{2}=4.8^{*} 10^{-34} \mathrm{~cm}^{6} / \mathrm{mole}^{2} \mathrm{~s} \\
\mathrm{O}+\mathrm{O}_{3} \rightarrow \mathrm{O}_{2}+\mathrm{O}_{2} & \mathrm{k}_{3}=2.6^{*} 10^{-14} \mathrm{~cm}^{3} / \mathrm{mole}_{\mathrm{s}} \\
\mathrm{O}_{3}+\mathrm{O}_{2} \rightarrow \mathrm{O}_{2}+\mathrm{O}+\mathrm{O}_{2} & \mathrm{k}_{4}=4.1^{*} 10^{-27} \mathrm{~cm}^{3} / \mathrm{mole}_{\mathrm{s}} \\
\mathrm{O}_{3}+\mathrm{O}_{3} \rightarrow 3 \mathrm{O}_{2} & \mathrm{k}_{5}=7^{*} 0^{-26} \mathrm{~cm}^{3} / \mathrm{mole}_{\mathrm{s}} \\
\mathrm{PS}+\mathrm{h} v \rightarrow \mathrm{R}^{\cdot}+\mathrm{H}_{\left(\mathrm{CH}_{3}\right)} & \varphi_{2}=10^{-1} \\
\mathrm{O}+\mathrm{PS} \rightarrow \mathrm{R}^{\cdot}+\mathrm{OH} & \gamma_{1} \simeq 10^{-2} \\
\mathrm{O}+\mathrm{R}^{\cdot} \rightarrow \mathrm{RO} & \gamma_{2} \simeq 1 \\
\mathrm{O}_{3}+\mathrm{PS} \rightarrow \mathrm{ROO}+\mathrm{OH} & \gamma_{3} \simeq 10^{-3} \\
\mathrm{O}_{3}+\mathrm{R}^{\cdot} \rightarrow \mathrm{RO}+\mathrm{O}_{2} & \gamma_{4} \simeq 10^{-2} \\
\mathrm{O}_{2}+\mathrm{R}^{\cdot} \rightarrow \mathrm{RO} \mathrm{O}_{2} & \gamma_{5} \simeq 10^{-2} \\
2 \mathrm{O}+\mathrm{MgF}_{2} \text { (window) } \rightarrow \mathrm{O}_{2} & \gamma_{6} \simeq 10^{-4} \mathrm{p} \text { (torr) }
\end{array}
$$


where reactions 1-6 describe $\mathrm{O}$ and $\mathrm{O}_{3}$ formation and destruction homogeneous processes occurred during VUV (147nm) photolysis of air [5] whereas reactions 7-13 represent heterogeneous processes going on at the surface and on the VUV lamp window. The needed probabilities of heterogeneous processes for $\mathrm{O}$ and $\mathrm{O}_{3}$ particles were taken from [6,7]. Based on reactions kinetic described above and one-dimensional diffusion model the following differential equations for $O$ and $\mathrm{O}_{3}$ concentrations can be written:

$\partial[\mathrm{O}] / \partial \mathrm{t}=\mathrm{D}_{1}{ }^{*} \partial^{2}[\mathrm{O}] / \partial \mathrm{x}^{2}+\varphi_{1}{ }^{*} \mathrm{I}(\mathrm{x})^{*}\left[\mathrm{O}_{2}\right]-\mathrm{k}_{1,2}{ }^{*}[\mathrm{O}]^{*}\left[\mathrm{O}_{2}, \mathrm{~N}_{2}\right]^{2}-\mathrm{k}_{3}{ }^{*}[\mathrm{O}]^{*}\left[\mathrm{O}_{3}\right]$

$\partial\left[\mathrm{O}_{3}\right] / \partial \mathrm{t}=\mathrm{D}_{2}{ }^{*} \partial^{2}\left[\mathrm{O}_{3}\right] / \partial \mathrm{x}^{2}+\mathrm{k}_{1,2}{ }^{*}[\mathrm{O}]^{*}\left[\mathrm{O}_{2}, \mathrm{~N}_{2}\right]^{2}-\mathrm{k}_{3}{ }^{*}[\mathrm{O}]^{*}\left[\mathrm{O}_{3}\right]$

with boundary conditions:

$\mathrm{D}_{1} \partial[\mathrm{O}] /\left.\partial \mathrm{x}\right|_{\mathrm{x}=0}=1 /\left.4[\mathrm{O}]\right|_{\mathrm{x}=0}{ }^{*} \mathrm{~V}_{\mathrm{O}}{ }^{*} \gamma_{6} \quad \mathrm{D}_{2} \partial\left[\mathrm{O}_{3}\right] /\left.\partial \mathrm{x}\right|_{\mathrm{x}=0}=0$

$\mathrm{D}_{1} \partial[\mathrm{O}] /\left.\partial \mathrm{x}\right|_{\mathrm{x}=1}=1 /\left.4[\mathrm{O}]\right|_{\mathrm{x}=1}{ }^{*} \mathrm{~V}_{\mathrm{O}}{ }^{*} \gamma_{6} \quad \mathrm{D}_{2} \partial\left[\mathrm{O}_{3}\right] /\left.\partial \mathrm{x}\right|_{\mathrm{x}=1}=1 /\left.4\left[\mathrm{O}_{3}\right]\right|_{\mathrm{x}=1}{ }^{*} \mathrm{~V}_{\mathrm{O}_{3}}{ }^{*} \gamma_{3}$

where $p$ - is the $O_{2}$ partial pressure; $x$ - is the distance from VUV lamp; $D_{1}, D_{2}$ - are the diffusion coefficients for $O$ and $\mathrm{O}_{3}$ respectively; $\mathrm{I}(\mathrm{x})=$ $\mathrm{I}_{0}{ }^{*} \exp \left[-\mathrm{k}(\mathrm{p})^{*} \mathrm{x}\right]$ - the intensity of VUV lamp at the distance $\mathrm{x} ; \mathrm{k}(\mathrm{p})$ - the $\mathrm{O}_{2}$ absorption coefficient for $147 \mathrm{~nm}$ radiation.

The main results of computer calculation of atomic oxygen concentration at the polymer surface as a function of air pressure and the distance between polymer sample and VUV lamp are shown in Fig. 2,3.

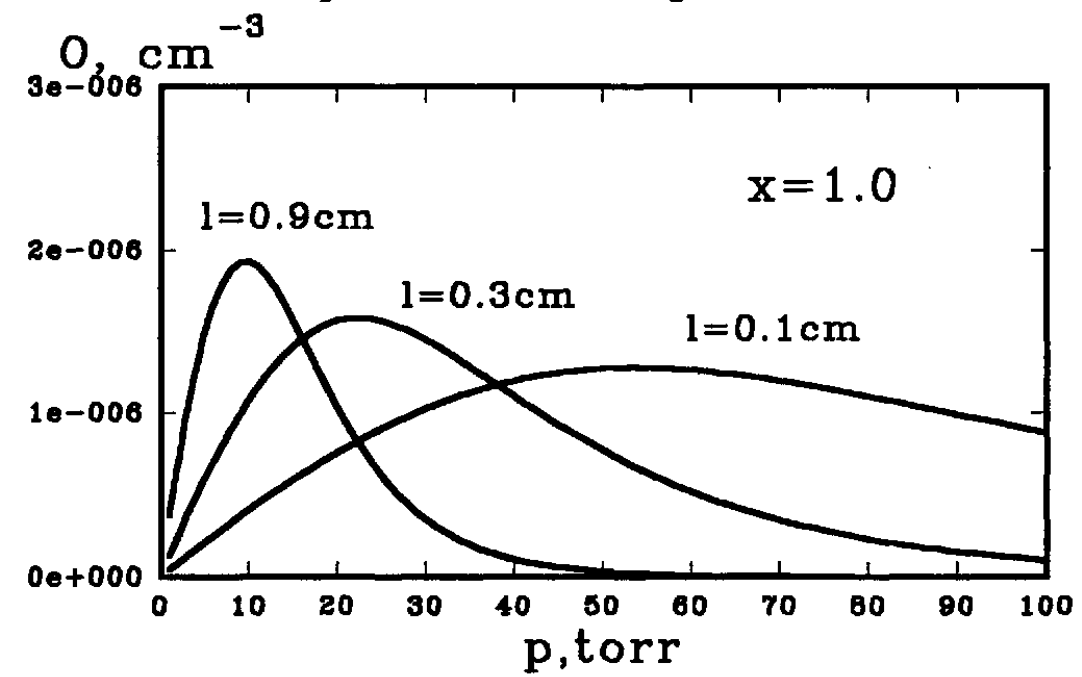

Fig.2 Concentrations of $\mathrm{O}$ atoms at the polymer surface as a function of oxigen pressure for the different distances from VUV lamp.

The concentration of atomic oxygen at the vicinity of polymer surface reaches a maximum value and fall off with further increase of pressure. It should be 
noted that higher maximum concentrations of $O$ are reached at higher distances but at lower $\mathrm{O}_{2}$ partial pressure. Ozon concentrations vs $\mathrm{O}_{2}$ pressure follow trends very similar to that obtained for atomic oxygen concentrations. However for our pressure range the value of ozone concentration was found to be 3-4 orders of magnitude lower than that of atomic oxygen. Therefore $\mathrm{O}_{3}$ molecules appear to play unimportant role in the photooxidation process under our experimental conditions. The intensity of VUV radiation according to LamberBear's law decreases exponentially with the increase of distance and $\mathrm{O}_{2}$ partial pressure. One can thus expect that the rate of photooxidation under the simultaneous action of VUV radiation and oxygen atoms will exhibit an extreme dependence on the air pressure. This conclusion was found to be corroborated by experimental data. As illustrated in Fig. 4-7, the concentrations of the main products of photooxidation $\mathrm{CO}$ and $\mathrm{OH}$ groups level off at the irradiation times more than $30 \mathrm{~min}$ and take the maximum value at the same pressure 2.5 torr for the irradiation distance $3 \mathrm{~cm}$.

The mechanism of VUV photooxidation process leading to the formation of $\mathrm{CO}$ and $\mathrm{OH}$ groups as well as intermolecular crosslinks can be represented by the following basic reactions:

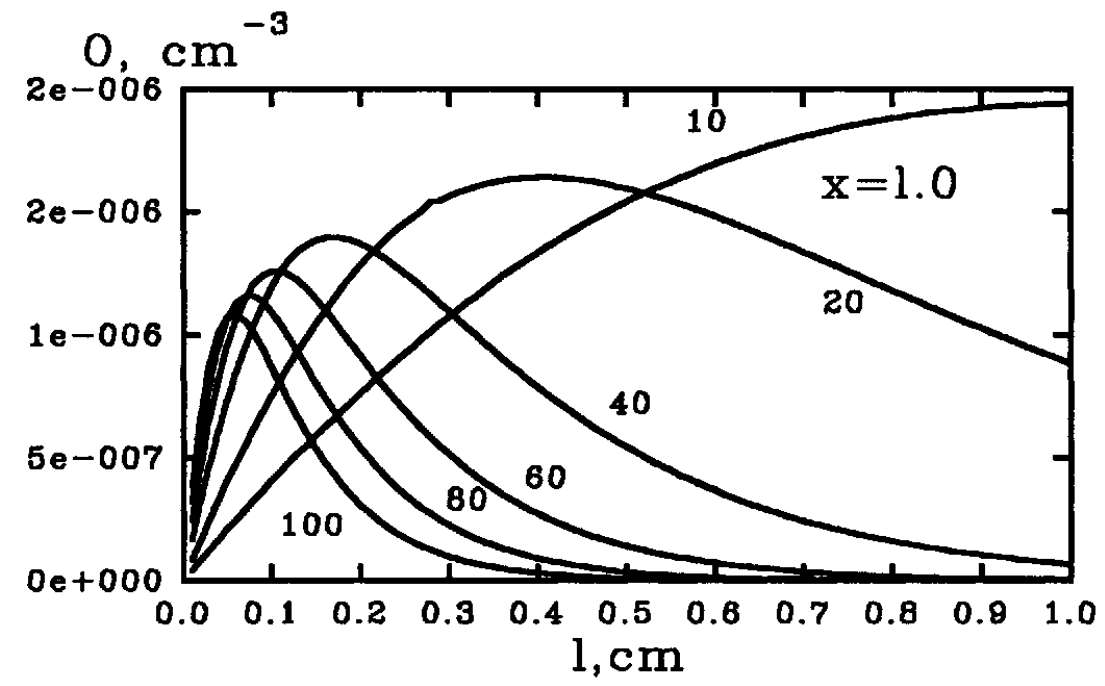

Fig.3 Concentrations of $O$ atoms at the polymer surface as a function of distance from VUV lamp for the different oxigen pressures $(10$, $20,40,60,80,100$ torr). 


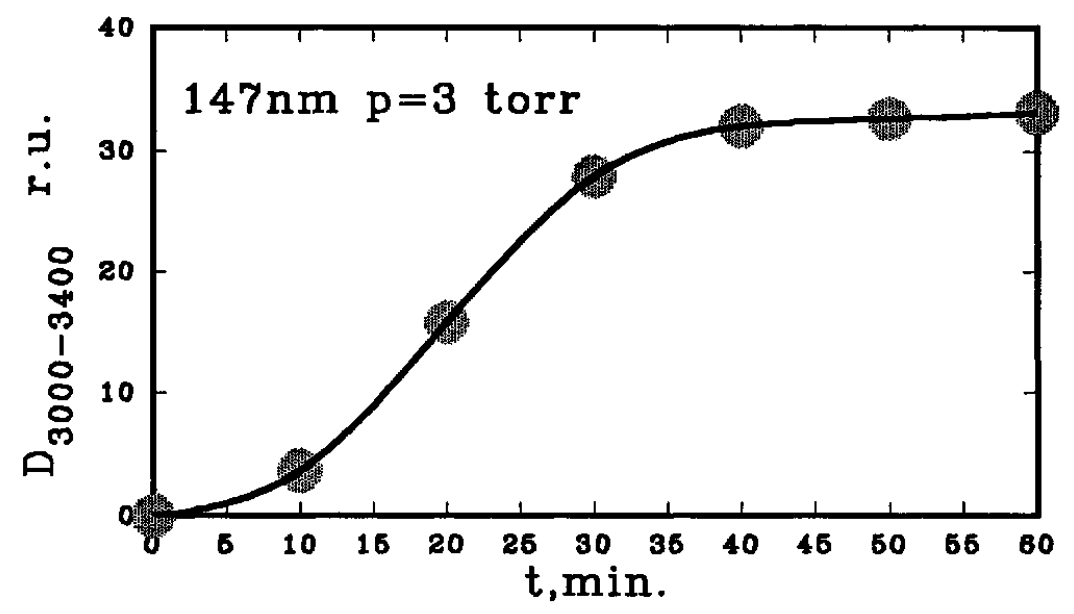

Fig.4 Evolution of $\mathrm{OH}$ groups at the surface of polymer I with VUV irradiation time.

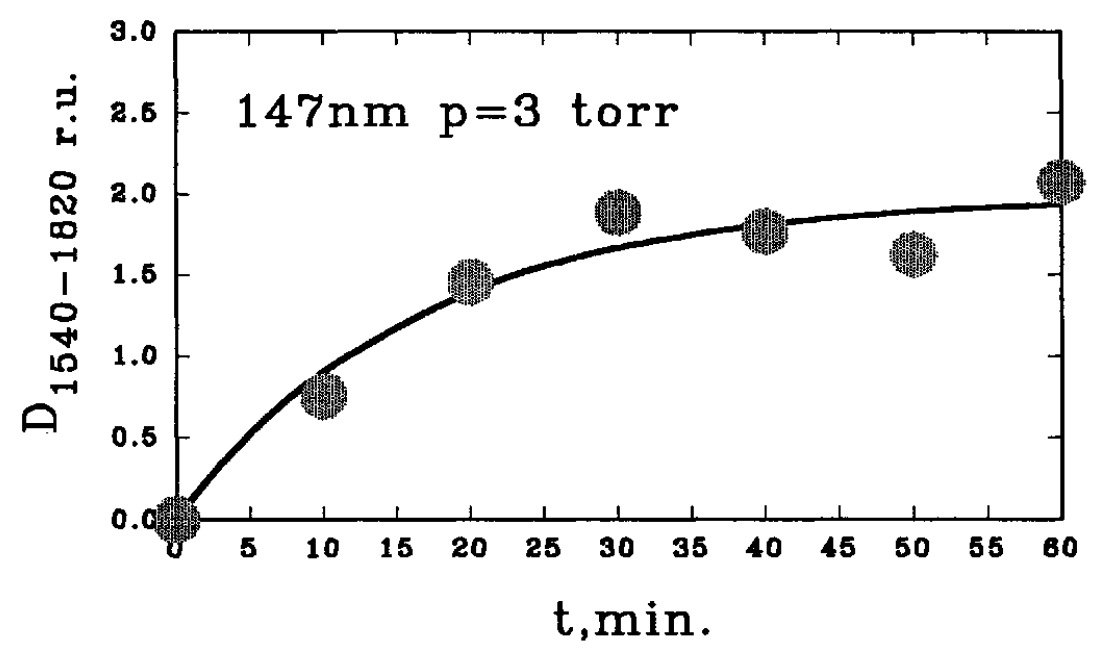

Fig.5 Evolution of $\mathrm{CO}$ groups at the surface of polymer I with VUV irradiation time.

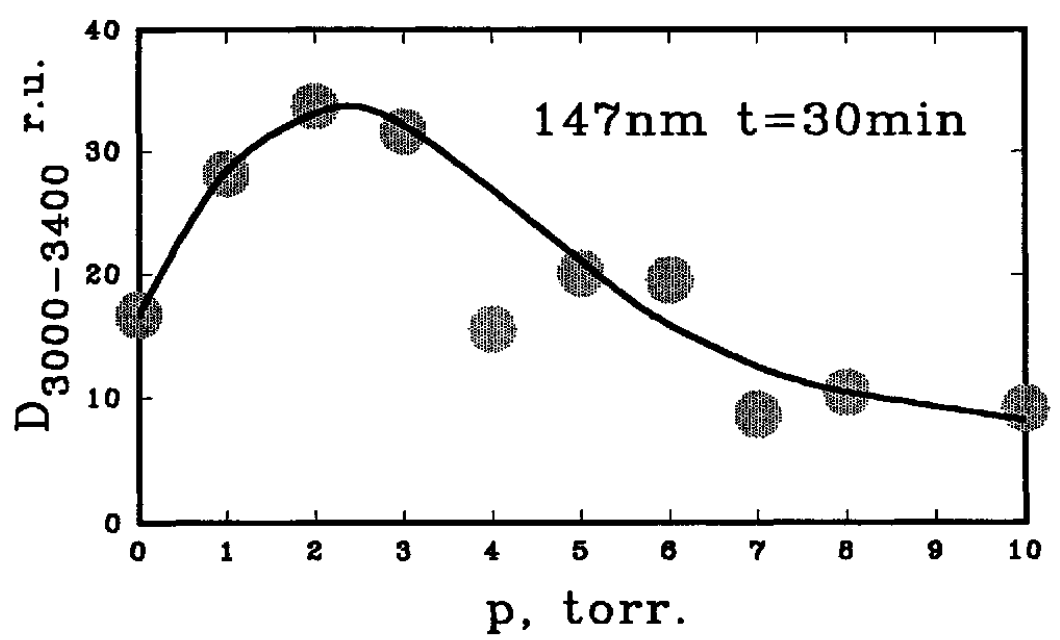

Fig.6 Effect of air pressure on the concentration of $\mathrm{OH}$ groups produced by VUV irradiation. 


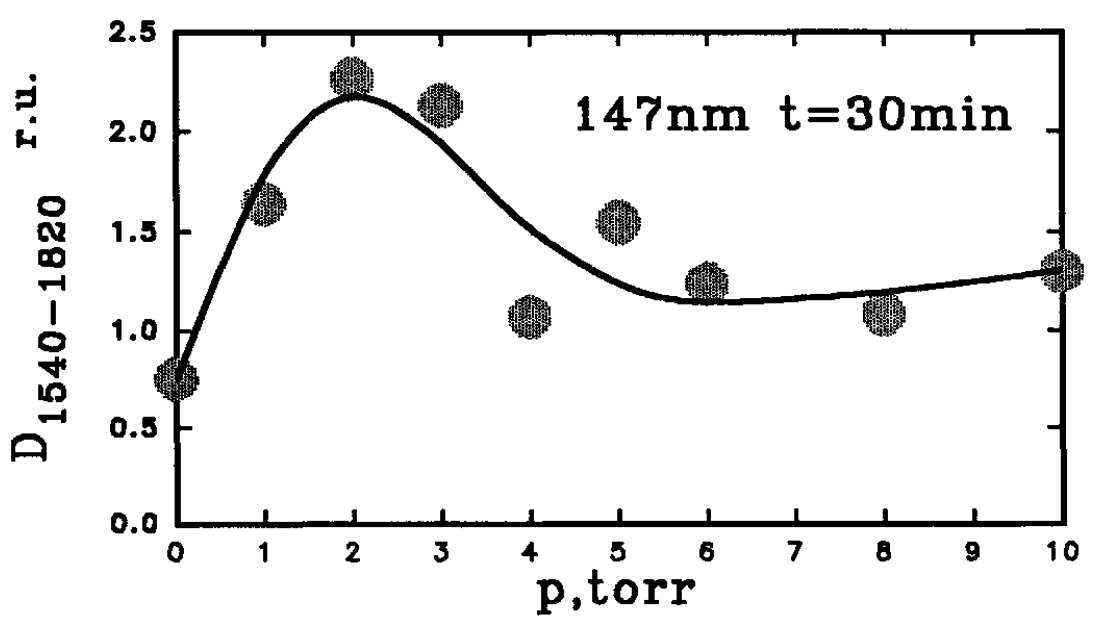

Fig.7 Effect of air pressure on the concentration of $\mathrm{CO}$ groups produced by VUV irradiation.

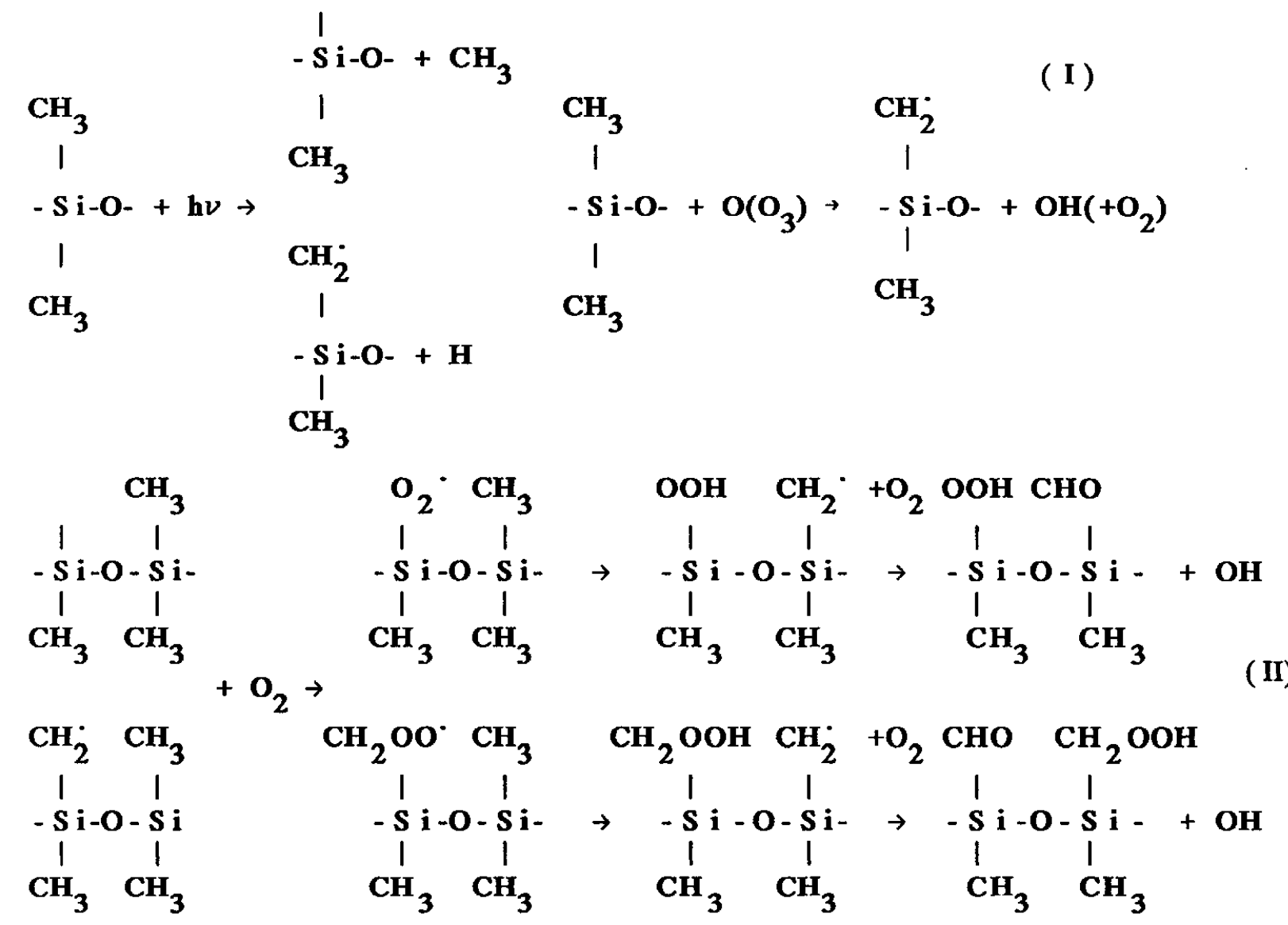




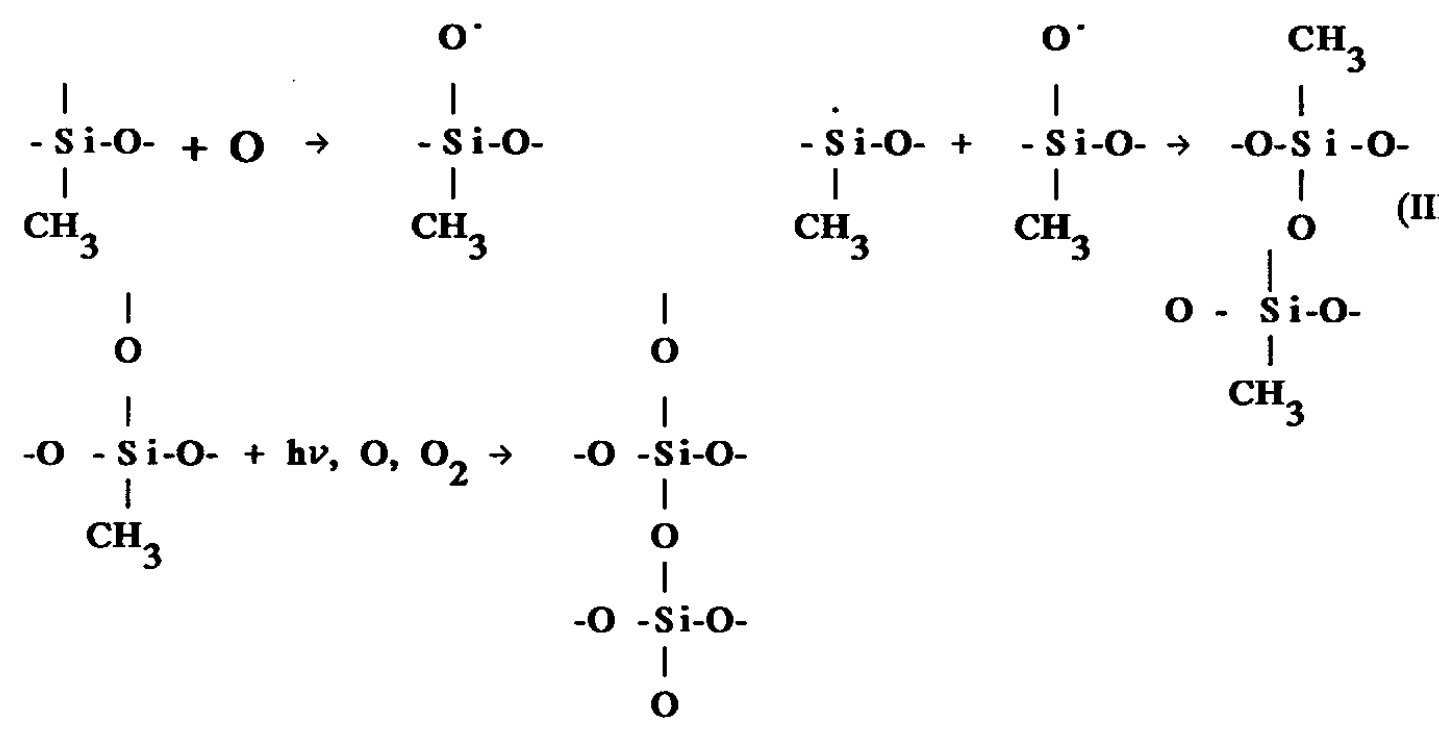

There are three groups of reactions shown above. The first one includes the reactions of radicals formation under the action of VUV radiation and oxigen atoms. The second one describes the reactions of radicals with $\mathrm{O}_{2}$ leading to the formation of peroxide radicals and further conversion to final products including $\mathrm{CO}$ and $\mathrm{OH}$ groups. . The third one represents the possible channals of intermolecular crosslinks formation in the reactions of radicals recombination.

It is necessary to emphasize that VUV photooxidation process can not be reduced only to an arithmetic sum of VUV irradiation and of atomic oxygen interaction with polymer surface. Earlier [8] we studied the action of VUV $(147 \mathrm{~nm})$ radiation and atomic oxygen on the surface of PE and PVC. It was found that the wight losses observed under the simultaneous action of VUV radiation and atomic oxygen were 2.5-3 times higher than those calculated as a sum of these two values taken from the separate experiments. We suggested that this phenomena resulted from "synergistic" effect between VUV and atomic oxygen.

\section{Conclusion}

The photooxidation of siloxane polymers under resonant VUV irradiation (wavelength $147 \mathrm{~nm}$, intensity $10^{15}$ quant $/ \mathrm{cm}^{2} \mathrm{~s}$ ) in the presence of air leads to the formation of $\mathrm{CO}, \mathrm{OH}$ groups and intermolecular crosslinks. The concentrations of $\mathrm{CO}$ and $\mathrm{OH}$ groups level off for irradiation times more than $30 \mathrm{~min}$ and reach the maximum value at 2.5 torr with the increase of air pressure in the range 0.1-100 torr. The effect of pressure on the rate of $\mathrm{CO}$ and $\mathrm{OH}$ formation closely similar to the pressure dependence of atomic oxygen 
concentration at the polymer surface. This suggests that the action of atomic oxygen in conjunction with VUV irradiation is responsible for the formation of $\mathrm{CO}$ and $\mathrm{OH}$ groups. For the first approximation the photooxidation mechanism can be describe by the reaction sequence allowing for initiation, oxidation and recombination of free radicals under the action of VUV radiation $\mathrm{O}_{2}$ and $\mathrm{O}$ particles. Macroradicals at the polymer surface are generated primarily by VUV irradiation and reactions with oxygen atoms. Oxidation of macroradicals and products formation occurs in the reactions with $\mathrm{O}_{2}$ molecules. The intermolecular crosslinks via oxygen atoms are formed by the radical recombination reactions.

\section{References}

1. I.G. Valunin, Z.I. Moroz, G.V. Gjavrishvily, L.S. Chabrova in "Polymers and Biomaterials", Elsevier Science Publishes B.V., (1991)p501.

2. A.E. Arbatskii, A.K. Vakar, A.V. Golubev, E.G. Krasheninnikov, V.V. Liventsov, S.O. Macheret, V.D. Rusanov, A.A. Fridman, High energy chemistry (Rus.), 24(1990)N3p256.

3. S.A. Yakovlev, Optical-mechanical industry (Rus.) (1978)N4p52.

4. Yu.N. Dorofeev, V.E. Scurat, High energy chemistry (Rus.), 22(1988)N3p245.

5. H. Okabe, "Photochemistry of small molecules", Wiley, New York, c.213.

6. V.I. Grinevich, A.I. Maximov, V.V. Rybkin, High energy chemistry (Rus.), 16(1986)N6p547.

7. A.A. Popov, N.Ya. Rappaport, G.E. Zaikov, " Oxidation of oriented and strength polymers", (Rus.), Moscow, "Khimiya" (1987)p286.

8. A.N. Ponomarev, A.I. Maximov, V.N. Vasilets, V.M. Menagarishvily, High energy chemistry (Rus.), 23(1989)N3p286. 